\title{
Hipólito Unanue y la construcción del héroe. Análisis de la relación entre el Estado-nación y la sociedad peruana en su esfera cultural *
}

\author{
Carlota Casalino-Sen ${ }^{1,2}$
}

Resumen

Palabras clave
En octubre de 1927, se desenterró los restos de Hipólito Unanue, para reenterrarlos en el Panteón de los Próceres. Esta acción estuvo acompañada por diversos actos públicos dirigidos a transformar al médico Hipólito Unanue en un héroe fundador. El artículo analiza el contexto y los factores que incidieron para ello. Señala dos elementos que se debe tener en consideración: la comunidad de culto organizada en torno a la memoria del héroe y lo que representó para los médicos y para la sociedad peruana.Desde el fallecimiento de Unanue, la comunidad de culto organizada en torno a este personaje se incrementa, se consolida y se formaliza. Así, de una actitud espontánea de los familiares más cercanos de construir un mausoleo, se van incorporando la Facultad de Medicina, la Sociedad Patriótica de Fundadores de la Independencia y el Colegio y Gremio médicos. Papel importante también jugará la Revista Hipólito Unanue. Unanue es percibido por los médicos de inicios del siglo XX como el paradigma del profesional exitoso que moderniza la enseñanza de la medicina y su ejercicio práctico. También, como un alto funcionario con acceso a la toma de decisiones en las altas esferas del poder, frente a los virreyes y los primeros gobernadores republicanos. Es decir, se trata de alguien que combina de manera armoniosa su quehacer profesional con la capacidad de tener efecto directo en las decisiones de Estado. En ese sentido, hay plena empatía entre Unanue y la generación que lo llevó al Panteón de los Próceres.

Unanue, Hipólito; Perú, historia de la medicina; Perú, Panteón de los Próceres.

\section{Hipolito Unanue and the hero's construction. Analysis of the state-nation and Peruvian society relation in the cultural sphere}

\section{Abstract}

In October 1927, Hipolito Unanue's mortal remains were exhumed and then burried again at the Illustrious Citizens' Pantheon. This event was accompanied by various public acts directed to transform the physician Hipolito Unanue into a founding hero. The paper analyzes the various influencing contexts and factors. It emphasizes on two elements: the cult-organized community on the hero's remembrance and what he represented to medical doctors and the Peruvian society. From the time Unanue died, the cult-organized community on this personage increases,

\footnotetext{
* Texto presentado en el "Coloquio Internacional Unanue y su tiempo" organizado por la Red Peruana de Historia de la Ciencia y la Salud, los días 19 y 20 de agosto de 2005, con ocasión de conmemorar los 250 años del nacimiento de Hipólito Unanue.

1 Magíster en Historia. Profesora de la Facultad de Ciencias Sociales de la Universidad Nacional Mayor de San Marcos. Lima, Perú.

2 Profesora de Historia de la Pontificia Universidad Católica del Perú. Lima, Perú.
}

consolidates and formalizes. So, from a spontaneous attitude of his closer family on building a mausoleum, we observe the following incorporation of the Faculty of Medicine, the Independence Founders Patriotic Society, and the medical College and Union. The Journal Hipolito Unanue would also play an important role. Unanue is perceived by the beginning of the XX century physicians as the paradigm of the successful professional that modernizes both teaching and practice of medicine. Also, as a high official accessing high power social stratum he took decisions standing up to viceroys and the first republican governors. That is, we deal with someone who harmoniously combines his professional task with the capacity of acting directly on State decisions. In this way there is full empathy between Unanue and the generation that carried him to the Illustrious Citizens Pantheon. Keywords: Unanue, Hipolito; Peru, history of medicine; Peru, Panteon de los Proceres.

\section{Introducción}

El estudio de los héroes patrios modernos, y en este caso en particular, el caso de Hipólito Unanue en su dimensión de construcción heroica, se apoya en la línea historiográfica de incluir elementos 
culturales y simbólicos en el análisis de la invención de la nación y la nacionalidad, así como la relación que establecen éstas con la sociedad. Esta corriente sostiene que la nación no es un elemento natural e inherente a las sociedades cuyo origen se pierde en el tiempo, sino que en determinado momento cuando se vincula a lo político, requiere construirse, inventarse y transmitirse. ${ }^{\dagger}$

Este trabajo analiza el momento en el cual el Estado-nación decide incluir a Hipólito Unanue en el Panteón de los Próceres de la Nación por varias razones que entonces eran importantes y debían ser tomadas en consideración. Generalmente esas causas están vinculadas a los valores y principios fundacionales de la República. De esa manera, la generación que lo rescata participa en reforzar la invención de una tradición patriótica. Para ello recurre a desplazamientos por las principales calles de la ciudad, rituales de desentierro-re entierro y ceremonias públicas. Todas ellas son actividades que tienen por objetivo actualizar la memoria del personaje y fortalecer la construcción de la nación a partir de algunos íconos significativos para la comunidad de los peruanos.

Con la incorporación del médico Hipólito Unanue al Panteón de los Próceres se ratifica la vocación de rescatar de la historia a personajes civiles que contribuyeron a fundar y construir la República del Perú. Esta afirmación merece ser explicada. Cada generación que busca en el pasado héroes para recuperarlos y actualizarlos a través del ceremonial, tiende a escoger aquellos con los cuales se siente más identificado. Así, a veces se rescatan militares y a veces civiles. En el caso particular de Hipólito Unanue la generación que lideró políticamente la tercera década del siglo XX prefirió a los civiles.

Sin embargo, respecto a Hipólito Unanue, hay otro elemento que debe ser tomado en consideración. Adicionalmente a la decisión política de incorporarlo al Panteón, estamos ante una prueba contundente de la consolidación de un grupo de la sociedad. En efecto, los profesionales de la medicina tienen en ese período la fuerza suficiente para impulsar la presencia de uno de sus héroes fundacionales más reconocidos. Así, logran que su figura trascienda a dicho entorno y se proyecte hacia el conjunto de la sociedad $\$(1,2)$. Esto quiere decir que el rescate histórico de Unanue pasa a legitimar el liderazgo de los médicos, portavoces en ese entonces del discurso moderno que la sociedad peruana está buscando $\left(^{3}\right)$. No es casual, por lo tanto, que entre 1924 y 1926 se haya publicado la primera revista de historia de la medicina que llevó por nombre Unanue $\left(^{4}\right)$. En ese sentido, se establece una relación recíproca entre Unanue -el personaje histórico que protagonizará los cambios más modernos del período tardo colonial y del auroral republicano- y la generación de médicos que lideraron el discurso modernizador de las primeras décadas del siglo XX.

Esta búsqueda tampoco estaría ajena a la sensación que se busca proyectar durante la tercera década del siglo XX de encontrarse frente a una nueva sociedad y un nuevo proyecto que reflejaría dicha percepción. Ésta de alguna manera buscaría institucionalizarse a través del lenguaje, por ello este período se denominó la 'Patria Nueva' $\left.{ }^{5,6}\right)$.

El homenaje a Hipólito Unanue de incorporación al Panteón de los Próceres se llevó a cabo en octubre

Sobre este tema se ha escrito desde distintas perspectivas teóricas y realizado análisis de procesos históricos puntuales. Sin embargo, considero que de manera precisa me refiero a: Ernest Gellner.- Encuentros con el nacionalismo. Alianza Universidad, Madrid, 1995 y del mismo autor: Naciones y nacionalismo. Alianza Editorial, España, 1997; Benedict Anderson.- Comunidades imaginadas. Reflexiones sobre el origen y la difusión del nacionalismo, FCE, México, 1997; Anthony D. Smith.- Nacionalismo y modernidad. Ediciones Istmo, España, 2000; Eric Hobsbawm y Terence Ranger (eds.).- La invención de la tradición. Editorial Crítica, Barcelona, 2002; Antonio Annino y François Xavier Guerra (Comps.).- Inventando la nación. Iberoamérica, siglo XIX. FCE, México, 2003; Álvaro Fernández Bravo (Comp.).- La invención de la nación. Lecturas de la identidad de Herder a Homi Baba. Manantial, Buenos Aires, 2000 y Tomás Pérez Vejo.- Nación, identidad nacional y otros mitos nacionalistas. Ediciones Nobel, España, 1999.

* Los médicos son uno de los cuerpos profesionales más organizados y que tienen su propio panteón heroico con claro reconocimiento de toda la sociedad. Así, Hipólito Unanue, Cayetano Heredia y Daniel A. Carrión, son sus principales iconos. En ese sentido, si consideramos que Unanue (héroe fundador), Heredia (héroe ordenador) y Carrión (héroe cultural) constituyen los íconos del cuerpo de médicos del país, estamos frente a una trilogía que va a consolidarse durante la primera mitad del siglo XX lo que permitirá que dichos héroes trasciendan el gremio médico y adquieran un lugar reconocido para el conjunto de la sociedad peruana. Ello no escapa que a su vez grupos al interior del cuerpo de médicos manifiesten su preferencia por alguno de los héroes sobre los otros. 
de 1927 con ocasión de ser la ciudad de Lima sede de la VIII Conferencia Sanitaria Pan Americana. Es decir un contexto académico de dimensión internacional es convertido en el momento idóneo para exhibir a uno de los iconos fundadores de la República.

\section{El héroe Hipólito Unanue: Una hipóstasis del modelo heroico}

Los héroes representan los valores, la tradición y los principios de determinados grupos humanos. Su figura contribuye a desarrollar el sentimiento de pertenencia en cada uno de los miembros que conforman una comunidad. Los estudios de estas figuras heroicas se hacen a través de conceptos y categorías que explican las funciones que cumplen y están en estrecha vinculación con la sociedad que los construye $(7,8,9)$.

De manera general, podemos ubicar a los héroes en tres grandes grupos clasificatorios: funcional, sistémico y estratégico. Conocer sus funciones nos acercará a las características particulares de cada uno de ellos y el rol que cumplen en su respectiva sociedad. Conocer de qué manera articulan a su comunidad nos dará información sobre el sistema en el cual están inmersos. Conocer qué están representando y qué proyectan a los otros (comunidades, países, futuras generaciones) nos permitirá conocer el proyecto de la comunidad. La comprensión de la figura heroica adquiere - por lo tanto- un interés político, social y cultural que abarca la relación entre el héroe y la sociedad a través del tiempo.

De manera particular, los héroes pueden tener virtudes competitivas (donde sobresalen la valentía y fortaleza) y también pueden tener virtudes cooperativas (es decir, donde predominan los actos de piedad y solidaridad). Sin embargo, la construcción e importancia de un héroe radica en que su recuerdo se mantenga vigente durante varias generaciones posteriores. Requiere que se organice en su entorno una comunidad de culto. Al margen del esfuerzo que el héroe realice, es la propia comunidad de manera permanente, a través de cada generación, la que rescata al héroe y se organiza alrededor de él. En ese sentido, podemos afirmar que lo más heroico es persistir en la memoria.

En el caso de Hipólito Unanue, podemos comprender la función de héroe desde una perspectiva estratégica, respondiéndonos a la pregunta ¿qué representó y qué buscaron proyectar los médicos con él? Las evidencias encontradas muestran que Unanue es percibido por los médicos de inicios del siglo XX como el paradigma del profesional exitoso que logra modernizar la enseñanza de la medicina y su ejercicio práctico. También se trata de un alto funcionario con acceso a la toma de decisiones en las altas esferas del poder, frente a los virreyes y los primeros gobernadores republicanos. Es decir, se trata de alguien que combina de manera armoniosa su quehacer profesional con la capacidad de tener efecto directo en las decisiones de Estado. ${ }^{\S}$

En ese sentido, estamos ante un héroe que reúne y representa virtudes cooperativas pues demuestra haber estado dispuesto - a pesar de su avanzada edad y de la incertidumbre que presentan los cambios políticos de principios del siglo XIX - de comprometerse con la construcción inicial de la República. Asimismo, manifiesta una actitud de héroe actuante, razón por la cual ejerce influencia sobre los demás y se convierte en un personaje estimulante para la acción, capaz de motivar las actividades de los médicos de inicios del siglo XX. Ambos aspectos (virtudes y acciones) son los elementos que se tomarán en consideración y que garantizarán la construcción de una comunidad de culto en torno a su memoria. Ésta busca garantizar que el recuerdo de este icono no se pierda y que más bien trascienda a dicha comunidad y se proyecte al conjunto de la sociedad peruana.

\section{El ceremonial de desentierro y de}

\section{desplazamiento, una apoteosis invertida}

La ceremonia propiamente dicha, de incorporación de Unanue al Panteón de los Próceres constituye un conjunto compuesto por la suma de tres pequeñas ceremonias y dos desfiles cívico-patrióticos para lo cual se destinan dos días consecutivos.

La primera ceremonia se llevó a cabo en el Cementerio General y consistió en la exhumación de

$\S \quad$ Un análisis de la figura de Hipólito Unanue desde la perspectiva de su función como mediador cultural puede consultarse en Carlota Casalino Sen.- Hipólito Unanue y la ciencia ilustrada en el Perú, en: Scarlett O'Phelan Godoy y Carmen Salazar-Soler (editoras). Passeurs, mediadores culturales y agentes de la primera globalización en el mundo Ibérico, siglos XVI-XIX. PUCPIFEA, Lima, 2005. 
los restos. Luego se desarrolla el desfile que transporta los restos de Unanue a la Academia de Medicina. La segunda ceremonia es el homenaje que los médicos rinden a su 'padre' en el local institucional de estos profesionales, y será el lugar donde pasará la noche. Al día siguiente se lleva a cabo el segundo desfile, para trasladar a Unanue desde el local de la Academia Nacional de Medicina al Panteón de los Próceres. La tercera y última ceremonia será la central, pues en el Panteón se le rendirá homenaje con los honores correspondientes a un Presidente de la República.

A efectos de analizar este proceso de exhumación, traslado y re entierro, en primer lugar describiremos brevemente cada etapa y en segundo lugar presentaremos el análisis correspondiente. Para ello el conjunto de cinco pequeñas ceremonias las he agrupado en dos etapas. La primera comprende el primer tramo de la ceremonia llevado a cabo en el cementerio, el desplazamiento hasta la Academia de Medicina y la ceremonia celebrada en ese recinto, donde analizaremos los principales discursos. De igual manera procederé con la segunda etapa, que se inicia con el desplazamiento de la Academia al Panteón, la ceremonia en el Panteón que culmina con el re entierro en dicho lugar. Ahí nuevamente se analizará el ritual del desplazamiento y los discursos pronunciados.

De acuerdo a la crónica publicada en el diario 'El Comercio', la primera ceremonia se llevó a cabo en el Cementerio General y debía contar con la presencia de personas previamente elegidas y que constituyeron parte del protocolo. Todas ellas representaban los distintos círculos o grupos de pertenencia de Unanue: familiar, profesional, gubernamental - poder ejecutivo-y fundadores de la Independencia; así como los representantes de las instituciones más importantes de la sociedad: Alcalde de Lima, altos miembros de las Fuerzas Armadas y delegados de instituciones científicas quienes - por la función que ejercen-son una representación de la sociedad. Los asistentes debían observar la exhumación y reconocer que efectivamente el cadáver desenterrado correspondía a Unanue ${ }^{\prime}$.
Luego de lo cual se procedió al levantamiento del acta de exhumación, el que serviría para realizar la transferencia formal del cadáver, puesto que pasaría de la custodia del Cementerio General a la custodia del Decano de la Facultad de Medicina en representación de los médicos quien lo recibiría para trasladarlo al interior de la ciudad. Este ceremonial aparentemente simple, guarda un profundo significado, pues se trata de sacar al personaje del espacio destinado por la sociedad para albergar a sus difuntos - cementerio-, y reincorporarlo al espacio destinado a la sociedad peruana del siglo XX - ciudad de Lima y capital de la República - para que cumpla nuevas funciones.

Una vez culminado dicho ceremonial se inicia el desfile donde se lleva en procesión el cuerpo de Unanue. El desplazamiento por las calles de la ciudad estuvo encabezado por una guardia militar y tuvo como punto de llegada las instalaciones de la Academia Nacional de Medicina y el Círculo Médico ubicados en el Parque de la Exposición, es decir, un lugar donde se concentran las modificaciones urbanas más elocuentes de la modernización de ese entonces. Una vez que la comitiva llegó a su primer destino se celebró la segunda ceremonia que implicó varios discursos así como también velar los restos de Unanue hasta el día siguiente.

Si analizamos lo que hemos expuesto en este primer tramo del ceremonial, podemos afirmar que estamos frente a un ritual que reproduce de manera inversa un funeral apoteósico ${ }^{\rrbracket}\left({ }^{10}\right)$, con el cual se busca volver a incorporar a Unanue a la sociedad en calidad de padre fundador de la nación. Para ello es necesario transfigurarlo a través de un complejo ceremonial que condensa varias funciones estudiadas por la Antropología y la Historia (la función del xoanon, la construcción de la comunitas y el procesamiento de la muerte social). Nótese que este proceso de transfiguración posee un carácter cívico - sagrado, de ahí que consta de una simbología recargada.

La primera función asociada al xoanon, implica el juego mostrar-ocultar **. Éste se cumple a través

11 Las crónicas de este ceremonial fueron publicadas en varios periódicos de la época, puede verse por ejemplo El Comercio del 15 al 17 de octubre de 1927.

\Uno de los ejemplos históricos más representativos lo constituyen los funerales apoteósicos de los emperadores romanos quienes a través del ritual eran transfigurados en dioses.

** Sobre este tema, Jean Pierre Vernant establece los vínculos entre la estatuaria y su papel en la representación de los dioses, que dicho sea de paso también está vinculada a la representación de los muertos. Con este tipo de representación se busca satisfacer la necesidad de hacer visible lo invisible. 
de la etapa del desentierro. Así el ataúd es sacado del mausoleo familiar ubicado en el Cementerio General, e incluso los restos óseos de Unanue son expuestos a la intemperie, donde de manera explícita se exige el 'reconocimiento' de los restos por todos los representantes de la sociedad que se encontraron presentes en el cementerio. Luego se inicia la segunda parte de este binomio - 'ocultar' - que es ejecutado en el momento en que se trasladan los restos de un ataúd a otro, se introduce el acta del desentierro y se vuelve a cerrar el segundo ataúd. Sin embargo, el hecho de guardar los restos en el nuevo ataúd no significa la culminación del 'proceso de ocultar' propiamente dicho, porque esta etapa se completa recién cuando el nuevo ataúd es guardado en el sótano del Panteón. ${ }^{\dagger \dagger}$

Otro aspecto central de la función que cumple el xoanon es el carácter de talismán que posee y cuyas influencias son percibidas por todos los involucrados en este ceremonial $\left.{ }^{*}{ }^{11}\right)$. En ese sentido, el tener los restos de Unanue en determinados momentos garantiza a quienes lo poseen recibir beneficios, protección y parte de sus poderes o virtudes. De ahí que el desplazamiento por las calles de la ciudad y las estaciones que recorre por las instituciones médicas también son un proceso que adquiere carácter sacro.

La segunda función - construcción de la comunitas - se cumple a través del desplazamiento urbano de manera ritualizada. Para ello es necesario utilizar un recorrido por calles y edificios simbólicos. El grupo que se encarga de dicho peregrinaje también está compuesto por representantes de la sociedad organizada en cuerpos, gremios e instituciones, distribuidos bajo un criterio jerárquico. Todos aquellos que acompañan el desfile, ya sea como parte de la comitiva o como parte de los espectadores, comparten la misma experiencia, esfuerzo, emociones y sentimientos, aspectos básicos en la construcción de una comunidad * $\left.{ }^{(12}\right)$.
La tercera función -el proceso de muerte socialimplicó en el caso de Unanue, la ceremonia, los discursos, velarlo en la sede de la Academia de Medicina y al día siguiente conducirlo a una nueva morada al interior del Panteón de los Próceres, después de introducirlo a la ciudad y desplazarlo por calles, plazas y edificios simbólicos que representan el recorrido de su incorporación a la sociedad bajo la calidad de ancestro. En esta etapa la comunidad a la que reingresa casi un siglo después de su fallecimiento ha decidido recuperar su presencia y ubicarlo en un lugar especial, que en este caso es el Panteón de los Próceres de la Nación. Por lo tanto, la muerte social le otorga un lugar de privilegio: cumplir la función de padre fundador para el conjunto de la sociedad peruana. ${ }^{\dagger}$

\section{El papel del discurso en la transfiguración del héroe. La vigencia de la sociedad predominantemente oral}

Hasta aquí hemos analizado el significado de las ceremonias y del ritual, y ahora deseo destacar de manera específica, otra parte del ceremonial, aquel que está constituido por los discursos y que tiene una participación importante en la transfiguración del ancestro en padre fundador de la patria. El discurso de elogio de Unanue tiene como objetivo evocar la memoria y la imagen del personaje, a través de la palabra. En ese sentido, la imagen que se busca construir del personaje por medio del discurso incluye no sólo las palabras utilizadas, sino también la entonación de la voz, las pausas, los gestos y el sonido de las palabras. Asimismo; requiere contar con un público dispuesto a escuchar y a identificarse tanto racional como emocionalmente con el personaje. El conjunto de estos elementos permite que los asistentes a la ceremonia elaboren una imagen individual de Unanue.

Sin embargo, el hecho que los discursos pronunciados en estas ceremonias fueran transcritos

$\dagger \dagger$ El xoanon como ídolo arcaico tiene muchos significados que han sido analizados por Jean-Pierre Vernant, Entre mito y política, FCE, México, 2002, pp. 153-158.

\$ La función del xoanón es el de otorgar estabilidad y beneficios a un grupo determinado, el mismo que está obligado a organizar un ritual en torno a este personaje, por ello el autor sostiene la importancia de la conservación de un símbolo que tiene valor de talismán, pues donde quiera que esté confiere al que lo posee el privilegio y la exclusividad de ciertos poderes.

* Víctor Turner sostiene que en las fases liminares del ritual se diluye la estructura de la sociedad y todos los participantes comparten una misma experiencia emotiva de carácter sagrado.

† Sobre el particular ver Jack Goody.- Representaciones y contradicciones. La ambivalencia hacia las imágenes, el teatro, la ficción, las reliquias y la sexualidad. Editorial Paidós, España, 1999. Este autor sostiene que la reliquia viene a ser una representación metonímica y está asociada a la peregrinación y la memoria, con funciones mediadoras. 
y publicados al día siguiente por la prensa escrita, permite que la construcción de la memoria de Unanue pase a ser compartida por todos aquellos que no presenciaron directamente el ceremonial, pero que pueden acercarse a su conocimiento a través de los periódicos. En ese sentido, la imagen que se construye se vuelve un eco de lo escuchado en la propia ceremonia, pero contribuye a su trascendencia. Ello garantiza que al menos, sea leído en otros lugares adicionales a la ciudad de Lima, y dependerá de la distribución de dicho periódico para que otros puedan también compartir esta experiencia.

Entonces, el discurso pronunciado para un público privilegiado es socializado por la prensa escrita para todos los demás que no asistieron a las ceremonias. En ese sentido, la crónica periodística narra el detalle de esta ceremonia y publica los discursos correspondientes. De todos los discursos, a mi parecer uno de los más elocuentes sobre el carácter cívico-sagrado de Unanue fue el pronunciado por el doctor Fortunato Quesada, quien era el Presidente de la Conferencia Sanitaria Pan Americana. Así, sostiene que el local del Círculo Médico ha sido transformado en un ambiente de 'recogimiento y majestad' pues los restos de Unanue en el edificio han convertido a éste, por un breve tiempo, en un santuario. Así señala:

"No ha podido haber mayor acierto que el de traer tan inconmensurable reliquia a que honre al máximo este hogar en que viven, en comunidad hermosa, todas las instituciones médicas, académicas y gremial de nuestro país. ${ }^{(8)}$

Unanue les muestra grandeza y lo hacen testigo de lo que han alcanzando hasta ese momento los médicos y el futuro promisorio que aún les queda recorrer como cuerpo de profesionales de la medicina. De esta manera, el discurso contribuye a resaltar el carácter cívico-sagrado de la ceremonia, la importancia del acontecimiento para la nación y los orígenes sociales del personaje.

Lo primero que debemos manifestar es que las palabras utilizadas son plenamente compatibles con las ceremonias y desplazamientos realizados en el marco de su incorporación al Panteón Nacional. El orador puso énfasis en que los restos de Unanue constituyen una reliquia, es decir son restos venerados con capacidad de transformar en sagrado aquellos espacios y lugares por donde pasan. En ese sentido, el edificio que es sede de todas las instituciones de los médicos, también se transforma temporalmente en un espacio sacro mientras permanezcan ahí los restos del héroe. Recordemos lo señalado líneas arriba, sobre el carácter de talismán del xoanon. Asimismo, se señala de manera explícita que Unanue preside en imagen y en espíritu las actividades que se realizan en dicho recinto. Con ello se pone de manifiesto la función paternal e inspiradora de Unanue para las generaciones de médicos peruanos. Estos, a su vez y de acuerdo al discurso, pueden mostrar que se encuentran en un nivel de madurez y pleno desarrollo, pues son capaces de vivir en 'comunidad armoniosa' las instituciones médicas, académicas y gremial. *

Considero que esa aseveración constituye el enlace entre la generación de la tercera década del siglo $\mathrm{XX}$ con su ancestro más reconocido, Hipólito Unanue, el personaje por el cual los médicos modernos se legitiman al encontrarlo - a través de su rescate histórico- como el paradigma que ellos necesitan. Nótese además, que esa búsqueda de legitimación a través de los ancestros, no se restringe al pasado colonial y a lo criollo, sino que la búsqueda de enlaces históricos más antiguos hace que se vincule a Unanue con una de las divinidades más importantes del Imperio Inca:

"[...] entre tanto volvamos todos nuestros pensamientos y nuestros corazones hasta ese catafalco. Allí está el ánima mater no solo de la medicina nacional, sino de la americana también. En este instante podemos exclamar, señores, deslumbrados por tanta sublimidad como en los pasados tiempos, de nuestros padres, los Incas, que desde ese altar nos preside el Sol de la Ciencia Médica Peruana." ${ }^{(13)}$

En ese sentido, es pertinente la aseveración de Burga, quien sostiene que este proyecto de la Patria Nueva es nacionalista y tiene un carácter indianista, pues los médicos de las primeras décadas del siglo $\mathrm{XX}$ reconocen en los incas a sus ancestros, se trata de pensar a la nación y buscar dónde están los puntos

Este hecho es particularmente importante, porque Unanue después de un siglo de haber fallecido logra convertirse en una figura de consenso al interior de los médicos, aspecto que no había podido ser alcanzado ni con Heredia ni con Carrión. Véase sobre este tema el artículo de Juan Murillo, Oswaldo Salaverry, Walter Mendoza, Gustavo Franco, Walter Calderón y Juan Rodríguez: Daniel Alcides Carrión y su contribución al imaginario cultural de la medicina peruana. An Fac Med Lima. 2002;63(2):148-9,54. 
comunes y de consenso ${ }^{\S}\left({ }^{14}\right)$. Ello también exige que se eleve la importancia de la historia, pues ésta viene a ser el canal o el vehículo donde se puede encontrar con certidumbre a los iconos fundadores.

Otro discurso que vale la pena mencionar, fue el pronunciado por el médico Hermilio Valdizán. Se trata del discurso de orden y donde se destacan aquellas virtudes y acciones de Unanue con las cuales se busca preservar su memoria. Es decir, estamos ante la construcción de un arquetipo heroico. Para lo cual Valdizán se remonta hasta la conquista española con el fin de llamar la atención acerca de la ausencia de médicos durante dicho período. Avanzado el siglo XVI solo hay un médico que destaque (Sepúlveda), en el XVII hay dos personas con prestigio que se dedican a la cura de enfermos (San Martín y Barchilón ambos vinculados a la institución eclesiástica). Sin embargo, el descubrimiento de los efectos curativos de la cascarilla y de la quina permiten que se abran cursos de medicina (Prima y Vísperas), los mismos que según el orador eran poco estimulantes para la formación profesional al ser demasiados teóricos. Respecto a la segunda mitad del siglo XVII se muestra crítico de Peralta Barnuevo y Rocha. Asimismo, señala que quien contribuyó a consolidar la mala reputación y poca estima de la sociedad colonial respecto a los médicos fue el poeta Caviedes, con sus versos en el Diente del Parnaso, donde al criticar fieramente a los hombres de la salud y mostrarlos por su flaqueza, ignorancia y vanidad, quiebra toda posibilidad de obtener prestigio social a través las actividades médicas. En conclusión, Valdizán sostiene que desde la conquista hasta el final del siglo XVII el ambiente es adverso para la medicina y para los profesionales que se encargan de esa tarea. 1

Recién el siglo XVIII es un período donde se inician las posibilidades de desarrollo para la medicina, pues llegan médicos extranjeros que modernizan la práctica de la medicina (Petit, Bottoni, Delgar, Cosme Bueno), respecto a este último comienza a establecer claras distinciones. Así, Hermilio Valdizán sostiene que el prestigio de Cosme Bueno era superior al de Peralta Barnuevo, porque Cosme Bueno no solo cuenta con la sabiduría de Peralta Barnuevo, sino que lo supera al concentrar su conocimiento en pocas ciencias y en ser un brillante maestro, formador a su vez de los que serán maestros de Unanue y de Dávalos.

Nótese entonces, que Valdizán formula una larga introducción antes de elogiar la figura de Unanue, porque ha preferido ubicar en el tiempo a este personaje. En este caso la historia de la medicina realza aún más al héroe, pues es uno de los que contribuirán al desarrollo institucional tanto de la enseñanza como de su ejercicio profesional. Así, la visión de la historia de la medicina que presenta Valdizán, es una caracterizada por ser evolutiva ascendente. Se parte de la nada, pues no hay nadie encargado de la curación de los enfermos, para ir incrementándose lenta y paulatinamente a lo largo de los siglos. La notoriedad se inicia en el siglo XVIII y gana un lugar propio con la generación de Unanue. Un siglo después, los médicos que le rinden homenaje y lo incorporan al Panteón, son parte de esa tendencia ascendente.

Efectivamente, conforme Valdizán nos presenta la biografía de Unanue, va delineando la figura de un "hombre nuevo", en el sentido de ser un hombre de orígenes sociales humildes, cuya fortuna y buen nombre es alcanzado por medio del trabajo, disciplina e inteligencia. Sin embargo, Unanue también es presentado como alguien que a través de redes y relaciones personales, logra articular y garantizar el éxito personal. Es decir, en Unanue se encuentra una combinación de hombre moderno con las mejores prácticas de antiguo régimen.

Unanue también es identificado como alguien con éxito, el mismo que es logrado a partir del prestigio obtenido con su formación profesional. Es decir, este 'hombre nuevo' logra ascenso y reconocimiento social a través de la educación y del ejercicio profesional, que en este caso es el de medicina. Entonces, si en el siglo XVII el médico no era aceptado socialmente, Unanue quiebra dicha actitud adversa que algunos sectores de la sociedad percibían respecto de los médicos. En ese sentido, quiebra el mito, pues con él y con los médicos de su generación, se abre la posibilidad de lograr una sólida ubicación en la sociedad a través de la práctica de la medicina. Así, Unanue abre el camino para que las siguientes generaciones de médicos obtengan prestigio producto de su quehacer.

\footnotetext{
$\$$ Al respecto Manuel Burga sostiene que es durante la Patria Nueva donde se producen una serie de circunstancias y cambios que obligarán a pensar a la nación como problema.

II El discurso completo puede leerse en El Comercio, 16 de octubre de 1927, p. 4.
} 
Otra característica de Unanue - resaltada por Valdizán- es la del difusor de lo más avanzado de las ideas científicas utilizando como medio para realizar para dicha tarea a la prensa escrita. Esta actividad, de publicista, también es una cualidad del hombre moderno, que tiene fe en la formación de la opinión pública a través del diálogo y discusión en lugares públicos y a través del texto, especialmente en la prensa. Por esta razón se destaca su participación en el 'Mercurio Peruano'. Asimismo, Valdizán señala la necesidad de rescatar toda la obra literaria y científica de Unanue para que su memoria no se pierda y porque esos escritos constituyen su legado para los médicos de las siguientes generaciones. En ese sentido, Unanue no sólo contribuyó a formar la opinión pública de los hombres contemporáneos a él, sino que también constituye él y sus obras - un referente para sus seguidores y para el futuro.

Otro elemento que vale la pena destacar es la argumentación de Valdizán en el sentido que Unanue no sólo es el padre de la medicina peruana, sino que es el padre de varias de las especialidades de ésta. Así, mencionando las obras y las acciones de Unanue, señala que es el padre de la cirugía, el padre de la enseñanza de la anatomía, el padre del estudio de la botánica, el padre de la medicina clínica, de la epidemiología, de la psicología e incluso de la pediatría.

Da la impresión que Valdizán estima necesario hacer explícito el aporte específico de Unanue en las distintas especializaciones de la medicina, porque se trata de buscar puentes donde se establezcan vínculos de identificación de la obra de Unanue con los médicos de las primeras décadas del siglo XX. Con ello se busca presentar ante el público una reinterpretación de Unanue para que siga siendo actual. Es decir, siendo los médicos la comunidad de culto más cercana para mantener viva la memoria de Unanue, lo primero que hay que garantizar es que los miembros de dicha comunidad sigan encontrando significados en dicho héroe. A partir de ello, puedan ratificar formalmente aquella identificación.

Luego Valdizán pasa a mencionar que la obra de Unanue es fundamental para la construcción de la nacionalidad y de la patria. Pensadores anteriores a Valdizán, como Prado, ya habían encontrado en la generación de los Amantes del País, de la cual Unanue formaba parte, los primeros atisbos de amor a la patria y por lo tanto los primeros embriones de la nacionalidad. Este aspecto se enlaza con los objetivos de la Patria Nueva, de encontrar en el pasado los referentes de la identidad nacional. Así, Unanue se convierte en un ejemplo de ese origen, donde la búsqueda de la nacionalidad tiene como eje el origen humilde, el reconocimiento social adquirido por el prestigio del ejercicio profesional, la importancia civilizadora de la educación y de la ciencia.

Así, la obra de Unanue también está vinculada a la eficacia en transformar los deseos de modernización de la enseñanza de la medicina en una realidad que repercutirá en el mediano y largo plazo, haciendo que en la enseñanza de la medicina se produzca un cambio cualitativo e inicie una etapa completamente nueva. Esta transformación no sólo ponía énfasis en la construcción de edificios nuevos, sino que estuvo acompañada de la cátedra novedosa, capaz de atender en comunidad profesional, aquellos problemas y casos que recogían de la propia sociedad. Así, investigación, docencia y el servicio a la sociedad dieron contenido y sentido a la nueva edificación.

Valdizán quiere demostrar en su discurso que la creación de la Escuela de Medicina constituye un acto heroico. En el sentido que erigirlo en un período adverso - como es el período de los conflictos de la Metrópoli por la invasión napoleónica- requiere de vigor, energía y decisión que sólo un hombre como Unanue era capaz de lograr. Es decir, se trata de un heroísmo muy distinto al que se consigue en el campo de batalla. Es uno que requiere una capacidad de persuasión y de colaboración de toda la sociedad. Es un heroísmo basado en la construcción de un proyecto que mejore a la sociedad, no que la destruya.

Esta obra también puede ser explicada a partir de quienes son sus principales impulsores. En ese sentido, es una apuesta ilustrada en el pleno sentido del término, con un estilo moderno de ejecución y de lograr sus propósitos. Quienes participan desde la sociedad a hacer realidad esta institución son los intendentes y otros funcionarios vinculados a las reformas borbónicas, los grupos económicos que se encuentran en auge y también los propios médicos. El apoyo político proviene del propio virrey, quien tal como sostiene Timothy Anna, constituye un líder capaz de tener iniciativa propia y distanciarse incluso de los vaivenes políticos de la Metrópoli. Desde una perspectiva social, la construcción de esta institución, siguiendo la percepción de Valdizán, es que se trata de una institución cuyos orígenes son similares a la vivida por los propios médicos. Es decir, una 
institución de orígenes humildes. Este rescate social pone en evidencia, los nuevos valores que se reivindican. Nuevamente estamos ante la búsqueda de construcción de una nacionalidad que se vincule no a los valores y principios aristocráticos, sino que refleja el espíritu de la Patria Nueva, que busca en las nuevas clases sociales su principal soporte de legitimación y aceptación.

Sin embargo, tampoco se trata de una labor aislada, Unanue forma parte de una generación, de una comunidad que apuesta por el cambio y la modernización. Así, no sólo se trata del aporte de la generación de los Amantes del País, sino también el valioso y más imperecedero aún, el aporte de la comunidad de médicos de la época por hacer todos los esfuerzos para establecer la enseñanza de la medicina y de la ciencia. Entonces, al destacar que todos los médicos tenían que iniciarse profesionalmente desde un nivel de flebotómanos, y luego ganar el privilegio del Rey y las gestiones de la Real Audiencia para conseguir los grados correspondientes, estamos ante un recorrido común desde orígenes humildes y niveles iniciales, hasta un espacio de reconocimiento social donde ya no son necesarios privilegios, sino cumplir con los requisitos modernos de aprobar los cursos y tener un desempeño eficiente.

El discurso de Valdizán culmina con las etapas finales de la vida de Unanue. Por ello lo menciona como uno de los principales fundadores de la república y su retorno final a las aulas en sus últimos días de vida. Ahí se completa la construcción de este arquetipo heroico. Pues se trata de un científico, un maestro, un gestor, estadista y sobre todo un amante del país que está dispuesto a sacrificar todo por construir la república evitando la anarquía y el conflicto violento ${ }^{`}\left({ }^{4}\right)$.

Este extenso discurso refleja la necesidad de los líderes médicos de ese entonces de articular su quehacer profesional con el proyecto nacionalista. De elevarse por encima de las diferencias existentes al interior de las instituciones médicas. Hermilio Valdizán tenía una percepción muy clara de la importancia y utilidad de recurrir a las raíces, los orígenes institucionales y a los personajes más representativos, aquellos que emergieron de momentos de crisis, que respondieron con inteligencia a los retos de la historia, para articular el presente y garantizar un futuro de excelencia. Como lo señalan otros autores, los períodos más importantes de la medicina peruana están asociados a la vigencia de un imaginario reflejo de una matriz cultural muy particular: misión histórica de contribuir a la reconstrucción institucional de la medicina, el desarrollo de la investigación científica a pesar de los factores adversos y de un contexto de pobreza, el fomento de la vocación docente para garantizar la continuidad a lo largo de las generaciones y el ser portadores de los valores éticos y morales de la sociedad peruana $\left({ }^{1}\right)$.

Entonces, de lo señalado hasta aquí considero que se ha logrado demostrar que las ceremonias, rituales y discursos de esta primera etapa de traslado de Unanue al Panteón de los Próceres de la Nación han cumplido el objetivo de transfigurar la imagen del personaje en un padre fundador. Ahora vamos a analizar la segunda parte de este complejo ceremonial, que consiste en el desplazamiento del cortejo que lleva a Unanue hasta el Parque Universitario y la ceremonia de recepción de los restos en el Panteón.

El domingo 16 de octubre de 1827 se llevó a cabo la etapa final de la ceremonia de incorporación de los restos de Hipólito Unanue al Panteón de los Próceres de la Nación. Según nos relata la crónica publicada al día siguiente en los diarios de la capital, a las 7:30 de la mañana se presentaron a la Academia de Medicina una compañía con banda y bandera del regimiento de artillería de costa. Ellos se encargarían de montar guardia y escoltar los restos. A las 10 de la mañana diversos regimientos debían hacer un camino humano entre el local de la Academia de Medicina y el Panteón:

"Dieciséis batidores del regimiento escolta frente a la Academia de Medicina.

El batallón naval abriendo calle desde la Academia de Medicina hasta la plazuela de Guadalupe

El regimiento de infantería $N^{o} 3$ abriendo calle de la plazuela de Guadalupe al Panteón de los Próceres

El regimiento de infantería $N^{o} 11$ en línea de secciones de a tres en el lado norte del Parque Universitario con frente al Panteón.

El grupo de artillería $N^{o} 2$ en línea de cargas en el lado norte del Parque Universitario a continuación del regimiento de infantería $N^{o} 11[\ldots]$

- De acuerdo a lo señalado por Marcos Cueto, el mediador entre los médicos profesionalizados e institucionalizados de las primeras décadas del siglo XX y los orígenes de la práctica de la medicina fue Hermilio Valdizán. 
También formaron en las calles laterales, la compañia de ametralladoras, el regimiento de caballería número 5 y el grupo de artillería número 2.

Estas tropas estuvieron al mando del jefe de la plaza, coronel don Julio Mindreau, quien tenía como ayudantes al mayor de la Barra y al Capitán Morales Bermúdez. " $\left({ }^{15}\right)$

Nótese que el importante desplazamiento militar, debe haber sido muy impresionante, especialmente para los delegados extranjeros. Estamos ante la construcción de un espectáculo que nos recuerda la pompa barroca utilizada en Lima en el siglo XVII, por la fuerte y recargada presencia de símbolos de poder. A esa misma hora, deberían presentarse diversas personalidades que participarían en el traslado acompañando los restos de Unanue. El protocolo, publicado también en los periódicos, señalaba claramente quiénes y en qué orden debían desplazarse.

Si comparamos la lista de los que acompañaron los restos de Unanue en la primera etapa del ceremonial - del cementerio al Círculo Médico-, con esta etapa final - del Círculo Médico al Panteón de los Próceres de la Nación-, comprobamos claramente la mayor importancia de esta segunda etapa (Tabla 1).

En efecto, en el caso de los representantes del Poder Legislativo, en la segunda etapa deben asistir comisiones de las cámaras legislativas, también deben asistir mayor número de funcionarios de diversas instituciones de la sociedad, incluyendo comisiones científicas, así como delegados extranjeros.

Por lo tanto, la coincidencia entre los círculos y redes de Unanue (familiar, profesional y estatal) con la que los médicos de la década de 1930 convocaron en la ceremonia de incorporación del héroe en el Panteón es plena. Esta es, efectivamente, la prueba que indica que la profesionalización, institucionalización y consolidación de los médicos en la sociedad peruana ha llegado a uno de sus puntos más importantes a lo largo de su historia ${ }^{* *}\left({ }^{4,16}\right)$.

Antes de retirar los restos de Unanue de la Academia Nacional de Medicina, se llevó a cabo una ceremonia, en la cual de manera simbólica los familiares transfieren la custodia de los restos de Unanue a la Facultad de Medicina. Para ello se pronuncian sendos discursos, entre los cuales están el del doctor don Hipólito Larrabure en nombre de los deudos.

“[...] Sale pues, de la custodia familiar con el beneplácito de todos sus descendientes, que orgullosos presenciamos la glorificación del prócer y queda confiado al cuidado de la nación, que refrenda con esta ceremonia oficial a la apoteosis en que cada peruano ha premiado ya, en su fuero interno, los méritos del patriota, del político y del eminente hombre de ciencia.

Permitidme, señor Ministro, dejar constancia de nuestro profundo agradecimiento al Supremo Gobierno, por el brillo y espontaneidad de este homenaje, realzado todavía con la bondadosa presencia de nuestros actuales huéspedes de honor, los señores delegados ante la VIII Conferencia Sanitaria Pan Americana." $\left({ }^{15}\right)$

Las breves palabras pero muy elocuentes del representante de la familia de Unanue presentan tres ideas centrales: a) los descendientes de Unanue han continuado con la tradición y han mantenido vigente la memoria de este personaje, b) es justo el homenaje y por lo tanto ellos complacidos entregan los restos de su antepasado al cuidado de la nación, y c) hacer énfasis en que esa glorificación es solo la formalización de una actitud colectiva mostrada por los peruanos de reconocimiento del aporte de Unanue a la fundación de la sociedad peruana.

El siguiente discurso corresponde al doctor Guillermo Castañeta, a la sazón Presidente de la Academia Nacional de Medicina. Se trata de un discurso bastante extenso pero muy directo en cuanto a los mensajes que quiere transmitir. De manera general puedo señalar que dicho discurso desarrolla cuatro ideas principales: a) la comunidad de culto dedicada a garantizar que la memoria sobre Unanue permanezca a lo largo del tiempo está conformada por la familia y por los profesionales de la medicina, b) el aporte de Unanue a la docencia y ejercicio de la medicina, c) la contribución de Unanue en la construcción de la independencia del Perú, d) el carácter heroico del personaje.

El orador al ser Presidente de la Academia Nacional de Medicina, se sabe que es la persona idónea para ser quien entregue los restos de Unanue al cuidado de la nación. Tanto el cuerpo de médicos, como los descendientes de Unanue, sienten que han

** Durante las primeras décadas del siglo XX se genera un proceso social bien interesante entre los médicos: se renuevan los estudios universitarios, se profesionaliza la medicina y se conforman asociaciones profesionales, todo ello permitirá que los médicos constituyan parte de la élite científica de ese período. Este proceso fue plenamente congruente con lo que sucedía en el resto de América Latina donde se consolidan las instituciones nacionales de salud en cada país. 
Tabla 1. Comisiones e instituciones científicas y particulares participantes en el acto.

\begin{tabular}{|c|c|c|}
\hline & $\begin{array}{c}\text { Desplazamiento } 1 \\
\text { del Cementerio al Círculo Médico }\end{array}$ & $\begin{array}{c}\text { Desplazamiento } 2 \\
\text { del Círculo Médico al Panteón }\end{array}$ \\
\hline $\begin{array}{l}\text { Representantes de } \\
\text { la familia } \\
\text { Representantes de las } \\
\text { instituciones médicas }\end{array}$ & $\begin{array}{l}\text { Deudos del extinto } \\
\text { Decano de la Facultad de Medicina } \\
\text { Presidente de la Academia Nacional } \\
\text { de Medicina }\end{array}$ & $\begin{array}{l}\text { Deudos del doctor Unanue } \\
\text { Decano de la Facultad de Medicina } \\
\text { Presidente de la Academia Nacional } \\
\text { de Medicina }\end{array}$ \\
\hline $\begin{array}{l}\text { Representantes } \\
\text { del Ejecutivo }\end{array}$ & $\begin{array}{l}\text { Edecán del señor presidente de la República } \\
\text { Señor Ministro de Fomento }\end{array}$ & Edecán del presidente de la República \\
\hline $\begin{array}{l}\text { Representantes de } \\
\text { las instituciones de } \\
\text { la sociedad }\end{array}$ & $\begin{array}{l}\text { Rector de la Universidad Mayor de } \\
\text { San Marcos } \\
\text { Alcalde de Lima } \\
\text { Comisión de la Sociedad de } \\
\text { Fundadores de la Independencia }\end{array}$ & $\begin{array}{l}\text { Comisiones de las cámaras legislativas } \\
\text { Rector de la Universidad } \\
\text { Alcalde de Lima } \\
\text { Sociedad de Fundadores de la } \\
\text { Independencia } \\
\text { Director de la Sociedad de Beneficencia } \\
\text { Pública de Lima } \\
\text { Prefecto del departamento } \\
\text { Generales y contralmirantes del Ejército } \\
\text { Consejo de Oficiales Generales } \\
\text { Comisiones científicas que se nombren } \\
\text { al efecto y particulares }\end{array}$ \\
\hline $\begin{array}{l}\text { Representantes del } \\
\text { extranjero }\end{array}$ & $\begin{array}{l}\text { Miembros de la VII Conferencia } \\
\text { Sanitaria Pan Americana }\end{array}$ & $\begin{array}{l}\text { Señores delegados a la VII Conferencia } \\
\text { Sanitaria Pan Americana } \\
\text { Misiones Naval Americana y Española } \\
\text { de Policía }\end{array}$ \\
\hline
\end{tabular}

cumplido con una de sus principales tareas: la de haber garantizado que la memoria de Unanue pueda ser transmitida de generación en generación. Es decir, ellos que conformaron una comunidad de culto durante casi cien años, ven satisfechas sus acciones al haber conseguido que este personaje pueda ser incorporado al Panteón nacional.

La segunda idea transmitida en el discurso es muy directa al explicar las razones por las cuales los médicos peruanos de la tercera década del siglo $\mathrm{XX}$ honran la memoria de Unanue. Ellos reconocen en Unanue a la persona que modificó positivamente las condiciones para revertir la percepción negativa que se tenía respecto a la medicina. Un hombre de ideas modernas, de acción eficiente y de valores tan altos que le otorgan la fuerza suficiente para enfrentar todas las adversidades que salen a su paso:

"La nación le debe también especial homenaje como creador de la patria independiente. Imagen de un coloso del pensamiento y de la acción, la figura de Unanue se destaca en nuestro pasado enorme en su conjunto, precisa en sus líneas; es la del primero de los próceres peruanos que nada omitieron para darnos patria libre, culta y progresista. Representa la sabiduría, la moral intachable, la voluntad enérgica y la tenacidad; es un hombre sintesis, de cualidades nobles, las que puso al servicio de su patria y la ciencia médica entonces incipiente. Por eso, sus ideales surgieron pronto como realidades, creaciones, a su genio de dinamismo a pesar del medio hostil y abúlico y de nuestra atmósfera tibia y nebulosa que parece apropiada tan solo para la vida relajada. Porque chocó con tantos obstáculos y los venció sin fuerza aparente ni violencia, fue grande, fue heroico y de memoria perdurable.

Su actividad se ejercitó con éxito sobresaliente en todos los campos de la vida.

Patriota de la independencia, sus trabajos lo colocan primero entre los primeros; ministro de gobierno de San Martín, organiza el caos y la falencia que dejara al virreinato y preside el primer Congreso Constituyente. Más tarde colabora en la obra del Libertador; es uno de sus firmes apoyos y queda, al retiro de éste, como Presidente del Consejo de Ministros y Jefe del Gobierno. Su labor política puede concretarse entre estas palabras: energía, honradez y lealtad.

Su patriotismo nunca desmentido le arranca sus últimos gritos y sus postreras palabras. El anciano venerable decepcionado, siente acercarse el nuevo caos de la anarquía y del derroche y desde su retiro, como padre de la patria, da la voz de alarma y combate el mal 
naciente con el consejo y la advertencia, inhabilitado ya para oponerle su personal esfuerzo.

Tal es la faceta política de Unanue, la modalidad de su labor que la patria premia en estos instantes colocándolo entre sus héroes. Así culmina nuestro gobierno su tarea constructiva. Uniendo sus esfuerzos por el progreso nacional, tan empeñoso como fecundo, la obra más noble y duradera de honrar a los próceres de la patria; a la vez que las creaciones materiales y sobreponiéndolo a ellas, cumple el imperativo de afirmar el alma nacional que alienta en el culto y devoción de sus muertos ilustres. Queda cumplida la entrega del sagrado depósito confiado al celoso cuidado de la Academia Nacional de Medicina. $[\ldots] ”\left({ }^{15}\right)$

El ser uno de los constructores de la patria independiente, le otorga un lugar legítimo entre los fundadores de la nación. Es percibido como un héroe ordenador, en tanto logra establecer los cauces para controlar y revertir el caos imperante. Encarna los valores de la lealtad, honradez y energía lo que le permite tener actuación sobresaliente en el período inmediatamente posterior a la independencia. El orador también reconoce al gobierno de Leguía, la grandeza de saber reconocer en el pasado los principios y las personas que hicieron realidad la construcción de la patria. Así, nuevamente los médicos ratifican en este discurso su aporte en la construcción de una nueva patria, que se enlaza con los orígenes más puros de la República. El héroe Unanue, es el mediador, entre el pasado y ese presente, y entre los médicos y los que toman las decisiones políticas en la Patria Nueva.

El siguiente discurso estuvo a cargo del doctor Eduardo Bello quien habló en representación de la Facultad de Medicina en su calidad de Decano. También estuvo encargado de entregar los restos de Unanue para que pasen al cuidado de la nación. El discurso, presenta un esquema similar al de Valdizán y al de Castañeta. Las cuatro ideas centrales de dichos discursos se repiten, pero se pronuncian en un orden diferente: primero se presenta al héroe, no sólo a la audiencia, sino a toda la población. Segundo, la comunidad de médicos de la Facultad hace explícito cuáles son los sentimientos que tienen hacia Unanue. Tercero, resalta la participación heroica de Unanue en la transición a la república. Cuarto, la entrega de los restos a la nación.

Nótese que son tres grupos, tres comunidades de culto, responsables de guardar los restos y mantener viva la memoria de Unanue: los descendientes, la Academia Nacional de Medicina y la Facultad de Medicina de San Fernando. Son estos tres grupos los que a su vez participan en la transferencia de la custodia de sus restos para que la nación asuma dicha responsabilidad una vez se incorpore a Unanue al Panteón.

\section{El desfile hasta el Panteón. Resignificación de una costumbre}

Como hemos expresado, el desfile fue espectacular, porque los cuerpos militares fueron desplazados por todo el recorrido hacia el Panteón de los Próceres, porque había banda de músicos y batidores que anunciaban el desplazamiento y porque la población participó masivamente como espectadora.

A estas alturas es pertinente recordar al lector que el desplazamiento por las calles - de población e instituciones organizadas - forma parte estructural de la cultura de la sociedad y cuyos orígenes se pierden en el tiempo. Las raíces de esta cultura se sostienen tanto en la costumbre andina prehispánica —el desplazamiento del jefe étnico-_, como de la sociedad colonial -el desplazamiento del Corpus Christi, entre otras procesiones - y de la tradición republicana inicial -el desplazamiento de la Constitución- en los actos de juramentación e incluso en las ceremonias apoteósicas de entierro de los caudillos y protagonistas centrales de las guerras de Independencia. Entonces, en el siglo XX esta costumbre es resignificada y utilizada en la invención de la tradición consistente en incorporar al Panteón de los Próceres de la Nación a un conjunto de personajes heroicos $\left({ }^{17,18,19}\right)$ (Figura 1).

Una vez ingresado los restos de Hipólito Unanue y los invitados a tan solemne ceremonia el Arzobispo de Lima se encargó de los responsos correspondientes. Luego tomó la palabra el Ministro de Salubridad de Costa Rica, quien puso énfasis en la imagen internacional del personaje: 'su patria es el mundo'. Luego toma la palabra Carlos Enrique Paz Soldán, presidente de la Conferencia, para finalizar con las palabras del Ministro de Fomento el señor Souza. Sin embargo, vale la pena resaltar algunas palabras pronunciadas por Carlos Enrique Paz Soldán:

“[...] Hipólito Unanue ya no es poseedor de los altos hechos de su vida magnifica, ni de las anticipadas y peregrinas concepciones de su noble espíritu: la Nación y el Gobierno las han tomado para sí, para ilustrar nuestro historial aumentar nuestra leyenda, para ennoblecer los anales de la vida nacional y para abrillantar el abolengo milenario de la Raza.

Por esto, al penetrar hoy, redivivo, Hipólito Unanue este templo venerable y sacrosanto, para que bajo la sombra 


$$
\begin{aligned}
& \text { ㅁำ }
\end{aligned}
$$

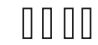

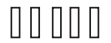

$$
\begin{aligned}
& \text { प०स०प } \\
& 16 \text { batidores } \\
& \text { [ } \\
& \text { Féretro con los restos del prócer } \\
& \text { Hipólito Unanue } \\
& \text { प्र०० }
\end{aligned}
$$

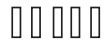

$$
\begin{aligned}
& \text { Escolta de Honor } \\
& \text { [] } \\
& \text { पर्प }
\end{aligned}
$$

Rector de San Marcos, Decano de Medicina, Presidente de Conferencia Panamericana

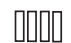

$$
\begin{aligned}
& \text { प्राप्या } \\
& \text { प्राप्याप } \\
& \text { प्रापाता }
\end{aligned}
$$

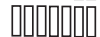

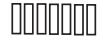

Delegados de la Conferencia Sanitaria Panamericana

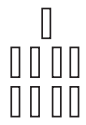

Alcalde de Lima, Sociedad de Fundadores de la Independencia

$$
\text { प] }
$$

Prefecto del Departamento, Director de la sociedad de beneficencia pública de Lima

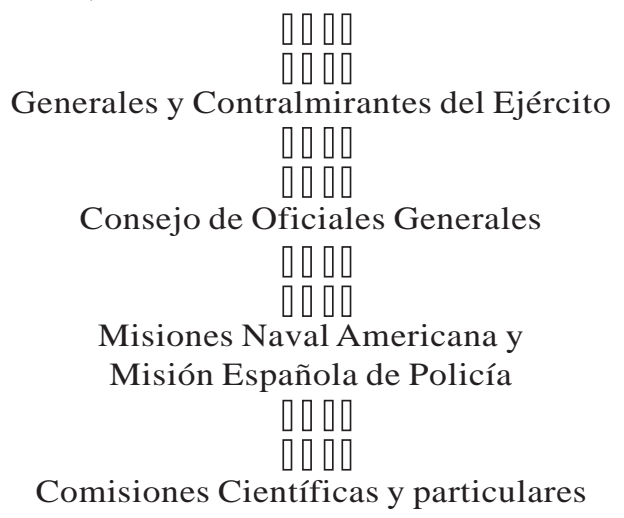

Comisiones Científicas y particulares

Figura 1. Esquema del desplazamiento de los restos de Hipólito Unanue desde el Círculo Médico al Panteón de los Próceres de la Nación ${ }^{+\dagger}\left({ }^{10}\right)$.

${ }_{\dagger \dagger}$ El esquema es muy ilustrativo del orden en el desplazamiento y está vinculado a la traslatio: procesión triunfal. 
quieta de los siglos que sus cúpulas encierran, duerma su sueño eterno y glorioso, velado por la patria, [...] Este acto que el Gobierno de la nación efectúa, tiene a los ojos del espíritu, el hondo sentido de una canonización civil. Hay ya un santo más de la ciencia y de la Patria. Y por esto, con la confianza de quien cumple su deber, voy a concluir con una oración al glorioso antepasado que venimos a consagrar.

Hipólito Unanue: al conjuro de la gratitud nacional te haz alzado de tu sepulcro en impresionante resurrección. Muéstrate otra vez a nuestros ojos y danos la luz de tu espíritu para encender en ella la antorcha del ideal y entra sereno a la inmortalidad, porque en esta hora tu presencia en el santuario de la peruanidad, siendo tu cuna Arica, es la más alta y pura lección que puedes dar de Justicia a la América!" (20)

Luego de lo cual los restos fueron depositados en el sótano, mientras sonaban 21 cañonazos.

\section{Conclusiones}

1. El desentierro, desplazamiento por la ciudad, las ceremonias, discursos así como el re entierro en el Panteón de los Próceres transfiguraron a Hipólito Unanue en un Prócer de la Nación. Acción que lo ubica en un lugar predominante de la sociedad peruana y cumpliendo nuevas funciones.

2. La existencia de una «comunidad de culto» construida en torno a Hipólito Unanue a lo largo de tantas décadas de la historia republicana muestra la fuerza de su presencia, y ratifica su importante papel en la historia de los peruanos. Esta comunidad de culto está asociada a los diversos círculos a los que perteneció Unanue y que van expandiéndose a lo largo de los años: la familia, los médicos, los altos funcionarios, la sociedad peruana. En ese sentido, Hipólito Unanue se transforma de un héroe fundador de los médicos en un héroe nacional.

3. La tercera década del siglo XX constituye uno de los principales momentos en la historia de la medicina y de los médicos en el Perú, porque se logra modernizar la enseñanza de la medicina, se profesionalizan los médicos, se organizan asociaciones profesionales y se establecen políticas de salud pública, de ahí que los médicos lideren el discurso moderno de la sociedad de ese entonces. Este proceso evidente de consolidación profesional es legitimado plenamente con la instauración de Hipólito Unanue en el Panteón de los Próceres.

4. El estudio de la relación entre la figura heroica de Hipólito Unanue y los médicos a lo largo de la historia da nuevas luces sobre la relación que estos últimos establecen con la sociedad. Se trata por lo tanto de una relación recíproca por medio de la cual la vigencia de la memoria del primero legitima el peso social e histórico de los segundos.

5. La memoria y figura de Hipólito Unanue continúa teniendo significados para los médicos de principios del siglo XXI. Pues aun se continúa celebrando reuniones que lo actualizan y lo mantienen vigente. Por lo tanto, de la generación actual depende que su memoria no se pierda.

\section{Referencias Bibliográficas}

1. Murillo JP, Salaverry O, Mendoza W, Franco G, Calderón W, Rodríguez J. Daniel Alcides Carrión y su contribución al imaginario cultural de la medicina peruana. An Fac Med Lima. 2002;63(2):141-59.

2. Zárate E. Los inicios de la Escuela de Medicina de Lima. Cayetano Heredia el organizador. Lima: ANR; 2005.

3. Mannarelli ME. Limpias y modernas. Género, higiene y cultura en la Lima del novecientos. Lima: Ediciones Flora Tristán; 1999.

4. Cueto M. Excelencia científica en la periferia. Lima: GradeConcytec; 1989. p. 22.

5. Contreras C, Cueto M. Historia del Perú Contemporáneo. Lima: Red para el desarrollo de las Ciencias Sociales en el Perú; 1999.

6. Klarén P. Nación y sociedad en la Historia del Perú. Lima: IEP; 2004.

7. Carlyle T. Los héroes. Barcelona: Ediciones Orbis; 1985.

8. Alvar J, Blázquez J (Eds.). Héroes y antihéroes en la antigüedad clásica. Madrid: Cátedra ediciones; 1997.

9. Bauzá HF. El mito del héroe. Morfología y semántica de la figura heroica. Argentina: FCE; 1998.

10. Arce J. Funus Imperatorum. Los funerales de los emperadores romanos. Madrid: Alianza Forma; 1990.

11. Vernant JP. Entre mito y política. México: FCE; 2002.

12. Turner V. El proceso ritual. Madrid: Taurus; 1988.

13. El Comercio. 16 de octubre de 1927. p. 4.

14. Burga M. La historia y los historiadores en el Perú. Lima: UNMSM-UPGV; 2005. p. 166-8.

15. El Comercio. 17 de octubre de 1927. p. 7.

16. Cueto M (Editor). Salud, cultura y sociedad en América Latina. Lima: IEP-OPS; 2000. p. 187.

17. Martínez J. Autoridades en los Andes, los atributos del señor. Lima: PUCP; 1995.

18. Kaulicke P. Memoria y muerte en el Perú antiguo. Lima: PUCP; 2004.

19. Dean C. Los cuerpos de los incas y el cuerpo de Cristo. El Corpus Christi en el Cusco colonial. Lima: UNMSM, 2002.

20. El Comercio. 17 de octubre de 1927. p. 8.

Manuscrito recibido el 15 de noviembre de 2005 y aceptado para publicación el 10 diciembre de 2005.

Correspondencia: Mag. Carlota Casalino-Sen

Colegio Real de las Culturas Peruanas.

Jr. Andahuaylas 348. Lima 1, Perú.

Correo-e: ccasalinos@unmsm.edu.pe / ccasali@pucp.edu.pe 